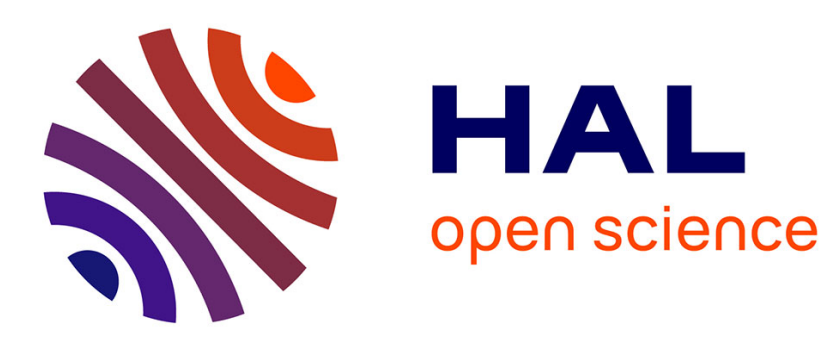

\title{
AN ANALYSIS OF FORECAST BASED REORDER POINT POLICIES : THE BENEFIT OF USING FORECASTS
}

\author{
Z. Babai, Yves Dallery
}

\section{- To cite this version:}

Z. Babai, Yves Dallery. AN ANALYSIS OF FORECAST BASED REORDER POINT POLICIES: THE BENEFIT OF USING FORECASTS. 12th IFAC Symposium on Information Control Problems in Manufacturing (INCOM06), May 2006, saint-Etienne, France. hal-00118643

\section{HAL Id: hal-00118643 \\ https://hal.science/hal-00118643}

Submitted on 5 Dec 2006

HAL is a multi-disciplinary open access archive for the deposit and dissemination of scientific research documents, whether they are published or not. The documents may come from teaching and research institutions in France or abroad, or from public or private research centers.
L'archive ouverte pluridisciplinaire HAL, est destinée au dépôt et à la diffusion de documents scientifiques de niveau recherche, publiés ou non, émanant des établissements d'enseignement et de recherche français ou étrangers, des laboratoires publics ou privés. 


\title{
AN ANALYSIS OF FORECAST BASED \\ REORDER POINT POLICIES : THE BENEFIT OF USING FORECASTS
}

\author{
Mohamed Zied Babaï and Yves Dallery \\ Laboratoire Génie Industriel \\ Ecole Centrale Paris \\ Grande Voie des Vignes \\ 92295 Châtenay-Malabry Cedex, France
}

\begin{abstract}
In this paper, we analyze forecast based inventory control policies for a non-stationary demand. We assume that forecasts and the associated uncertainties are given at the beginning of the horizon of forecasts. Two forecast based reorder point policies are proposed : the $\left(r_{k}, Q\right)$ and the $\left(r_{k}, Q_{k}\right)$ policies. These dynamic policies represent an extension of the classical discrete time $(r, Q)$ policy. The parameters of these policies are determined by using a sequential approach which satisfies a cycle service level. A numerical comparative study of these policies is developed enabling us to show the benefit of using them when forecasts are reliable. Copyright (C) 2006 IFAC
\end{abstract}

Keywords: inventory control, inventory policy, forecasts, forecast uncertainty

\section{INTRODUCTION}

Nowadays, in an industrial environment marked by an increasing competition, a better inventory management within supply chains is the key of customer satisfaction and cost reduction.

Many investigations have been performed since the 30's in order to develop new inventory control policies. Thus, there is a wide literature dealing with inventory control policies. Most of the models investigated in the literature assumes a stationary demand. The most known policies are the reorder point policy, denoted by $(r, Q)$ policy and the order-up-to-level policy, denoted by $(S, T)$ policy. Several other alternatives of these policies are developed such as : the $(s, S)$ policy which combines the two preceding policies by using at the same time a reorder point $s$ and a replenishment level $S$, the $(T, r, Q)$ policy which is a discrete time reorder point policy and the $(T, r, S)$ policy which is a discrete time $(s, S)$ policy. For more details on these policies, cf. (Zipkin, 2000) and (Silver and Peterson, 1985).

The customer demand is strongly influenced by several economic factors which make it more and more variable. In this context, the static policies given above are not suitable to control systems and it proves to be essential to use inventory control policies considering a non-stationary demand. Unfortunately, the literature in this area is relatively poor. There is some literature based on the work of (Scarf, 1959) and (Karlin, 1960). These works study optimal inventory control policies with an objective to minimize total inventory costs including backlog penalties. They consider stochastic demands over periods which are independent and identically distributed. They show that the optimal policy is a dynamic $(s, S)$ policy. Since the optimal policies' parameters can not be determined easily, only bounds on the optimal policies and their characteristics are obtained. 
During the last years, a body of literature is also developed by (Heath and Jackson, 1994), (Graves, 1999), (Lee et al., 1997) and (Chen et al., 2000) studying forecast based inventory management policies. This work considers auto-correlated nonstationary demand, where forecasts are obtained by using forecasting models and updated by using the MMFE model (Martingale Model of Forecast Evolution). They develop a dynamic order-upto-level policy where the replenishment level is computed in each period to satisfy a target service level. This work presents many advantages, the principle disadvantage is that all results are dependant on the forecast model and some assumptions of the inventory model remain restrictive.

In our work, we are not interested in the forecasting models. We assume that forecasts and the forecast uncertainty are an exogenous data given at the beginning of the horizon of forecasts. Our objective is to study simple inventory control policies assuming a non-stationary demand with pragmatic assumptions and an easy implementation. Two forecast based inventory control policies are proposed, namely : the $\left(r_{k}, Q\right)$ policy and the $\left(r_{k}, Q_{k}\right)$ policy. In this paper, the $\left(r_{k}, Q_{k}\right)$ policy is compared to the $\left(r_{k}, Q\right)$ policy and the discrete time $(r, Q)$ policy (denoted in the following by the $(1, r, Q)$ policy).

This paper is organized as follows : in section 2, we begin by describing the framework of the study and the assumptions. Then, we study the $\left(r_{k}, Q\right)$ and the $\left(r_{k}, Q_{k}\right)$ policies by giving the various parameters which characterize them. In section 3 , a numerical comparative study of these policies and the $(1, r, Q)$ policy is given which enables us to identify conditions under which the use of these policies may bring significant benefits. The conclusions are given in section 4 .

\section{FORECAST BASED INVENTORY CONTROL POLICIES}

\subsection{System description and assumptions}

In this paper, we study a pure single-stage and single-item inventory system with a nonstationary demand given in the form of uncertain forecasts. The system is not capacitated and the inventory replenishment requires a constant leadtime, as represented in Fig. 1.

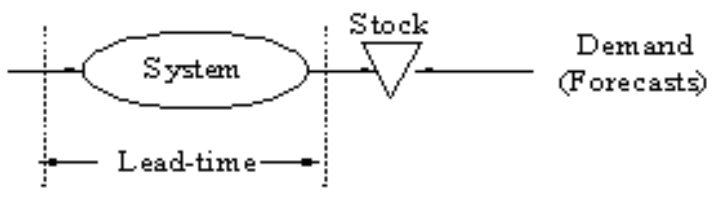

Fig. 1. The inventory system model
We assume that forecasts and forecast uncertainties are given at the beginning of the horizon of the forecasts. We also assume that forecast uncertainties are random variables independent and identically normally distributed over all the periods of the horizon with parameters $\left(0, \sigma_{F U}\right)$, as shown in Fig. 2.

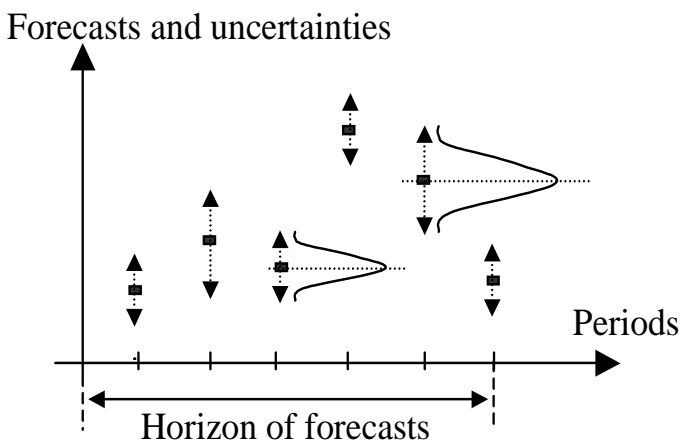

Fig. 2. The demand model

In practice, probability distributions of the forecast uncertainty can be determined by using historical statistics of demand and forecasts. We also suppose that the forecast uncertainty may be absolute or relative. The forecast uncertainty is absolute if it is independent of forecasts and it is relative, if it is proportional to the forecasts. If the forecast uncertainty is relative, the probability distribution is given in percentage.

We use a sequential approach to compute the parameters of the policies which means that the value of the ordering quantity is computed ignoring the impact upon it of the reorder point. To compute the safety parameter, we use a cycle service level objective, that means that we impose, at each cycle (time period between two successive orders), that the probability of not having a stock out is higher than a fixed value, called Cycle Service Level.

Let us introduce the notations used throughout the paper :

$F_{k}$ : forecast at period $k$

$L$ : replenishment lead-time

$I_{k}$ : inventory position at the end of period $k$

$C S L$ : Cycle Service Level

$A$ : fixed ordering cost

$h$ : holding cost

$H$ : number of periods in the horizon of forecasts

$C F U_{R}$ : cumulative forecast uncertainty over an interval $R$

$\Phi_{C F U_{R}}($.$) : cumulative probability distribution of$ $C F U_{R}$ 
$\Phi($.$) : standard normal cumulative probability$ distribution.

Since the forecast uncertainty is normally distributed in each period, the cumulative forecast uncertainty over an interval $R$ composed of $N$ periods is normally distributed with parameters $\left(0, \sigma_{C F U_{R}}\right)$, where $\sigma_{C F U_{R}}$ is given as follows :

- If the forecast uncertainty is absolute :

$$
\sigma_{C F U_{R}}=\sigma_{F U} \sqrt{N}
$$

- If the forecast uncertainty is relative :

$$
\sigma_{C F U_{R}}=\sigma_{F U} \sqrt{\sum_{j=1}^{N} F_{k+j-1}^{2}}
$$

$\Phi_{C F U_{R}}^{-1}(C S L)$ is called "maximal cumulative forecast uncertainty over the interval $R$ and for the cycle service level $C S L "$.

$\Phi_{C F U_{R}}^{-1}(C S L)=\Phi^{-1}(C S L) \sigma_{C F U_{R}}$

In the following, we briefly describe the $\left(r_{k}, Q\right)$ and the $\left(r_{k}, Q_{k}\right)$ policies, and we provide their parameters.

\subsection{The $\left(r_{k}, Q\right)$ policy}

In the $\left(r_{k}, Q\right)$ policy, the system is controlled in each elementary forecast period. At the beginning of each period $k$, if the inventory position falls below the reorder point $r_{k}$, a quantity $Q$ is ordered. The quantity ordered is received after $L$ periods. The inventory evolution in the $\left(r_{k}, Q\right)$ policy is represented in Fig. 3.

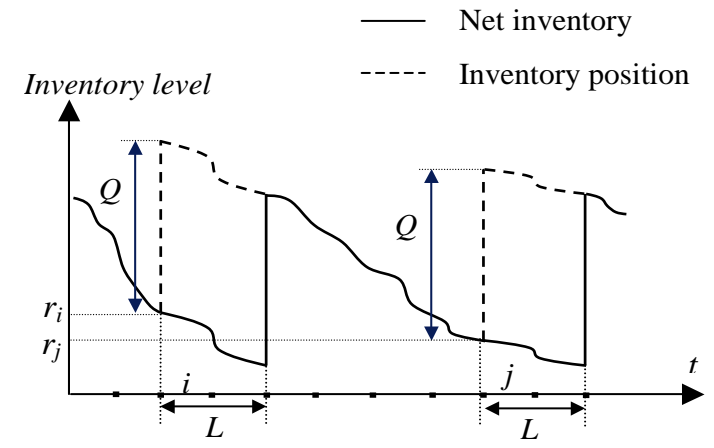

Fig. 3. The $\left(r_{k}, Q\right)$ policy

In this policy, the protection interval is equal to the sum of the replenishment lead-time $L$ and a single elementary forecast period (the single period must be added due to the discrete time review). Thus, the reorder point $r_{k}$ is equal to the cumulative forecasts and the maximal cumulative forecast uncertainty over $L+1$ periods. The reorder point is given by :

$$
r_{k}=\sum_{j=1}^{L+1} F_{k+j-1}+\Phi^{-1}(C S L) \sigma_{C F U_{L+1}}
$$

The reorder point $r_{k}$ is variable over time since the forecasts and the forecast uncertainty are variable over time. The second term in the expression of $r_{k}$ plays the role of the safety stock which, in the case of a relative forecast uncertainty, is variable from one period to another.

The quantity $Q$ can be computed by using the Wilson's formula, as follows :

$$
Q=\sqrt{\frac{2 A \sum_{i=1}^{H} F_{i}}{h H}}
$$

More details on this policy are given in (Babaï and Dallery, 2005) and (Babaï, 2005).

\subsection{The $\left(r_{k}, Q_{k}\right)$ policy}

The $\left(r_{k}, Q_{k}\right)$ policy is an extension of the $\left(r_{k}, Q\right)$ policy. Indeed, in the $\left(r_{k}, Q\right)$ policy, the ordering quantity is constant over the horizon and computed by using the Wilson's formula. In the $\left(r_{k}, Q_{k}\right)$ policy, we use a method developed to compute the ordering quantity which become variable.

In this policy, the system is controlled in each elementary forecast period. At the beginning of a each period $k$, if the inventory position is less than the reorder point $r_{k}$, a quantity $Q_{k}$ is ordered. The quantity ordered is received after $L$ periods. The inventory evolution in the $\left(r_{k}, Q\right)$ policy is represented in Fig. 4.

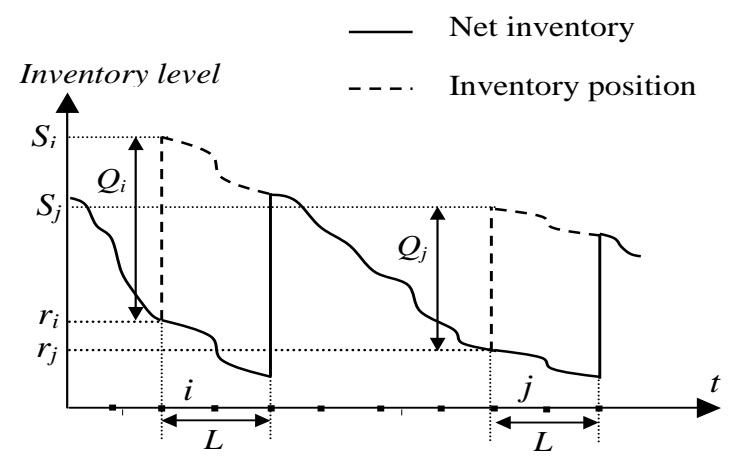

Fig. 4. The $\left(r_{k}, Q_{k}\right)$ policy

The protection interval in the $\left(r_{k}, Q_{k}\right)$ policy is also equal to $L+1$ periods. Thus, the reorder point $r_{k}$ is equal to the cumulative forecasts and the maximal cumulative forecast uncertainty over $L+1$ periods, and it is given by the following formula : 


$$
r_{k}=\sum_{j=1}^{L+1} F_{k+j-1}+\Phi^{-1}(C S L) \sigma_{C F U_{L+1}}
$$

In each period $k$, the ordering quantity $Q_{k}$ is computed by using an heuristic method which we developed as an extension of the Silver-Meal Heuristic (Silver and Meal, 1973). Indeed, the objective of the heuristic is to find the number of periods $N_{k}$ to be covered by the quantity $Q_{k}$ which is ordered at the beginning of period $k$ and received at the beginning of the period $k+L$, that minimizes the expected total cost, denoted by $C T\left(N_{k}\right)$.

The expected total inventory over $N_{k}$ periods $(k+$ $\left.L, k+L+1, . ., k+L+N_{k}-1\right)$, calculated at the beginning of period $k$ and denoted by $\bar{X}_{k}^{N_{k}}$, is given by :

$$
\bar{X}_{k}^{N_{k}}=\sum_{j=1}^{L+N_{k}} F_{k+j-1}+N_{k} \Phi_{C F U_{L+N_{k}}}^{-1}(C S L)
$$

Thus, the expected total inventory cost over $N_{k}$ periods, calculated at the beginning of a period $k$ is :

$$
C T\left(N_{k}\right)=\frac{A+h \bar{X}_{k}^{N_{k}}}{N_{k}}
$$

The key idea of the heuristic is to start with an initial value $N_{k}=1$, to calculate the expected total costs $C T\left(N_{k}\right)$ and $C T\left(N_{k}+1\right)$, then to increment $N_{k}$ in order to seek the first period $N_{k}^{*}$ for which $C T\left(N_{k}^{*}+1\right)>C T\left(N_{k}^{*}\right)$. If this condition is satisfied, at the beginning of period $k$, a batch of size $Q_{k}$ is ordered in order to cover the maximal cumulative forecasted demand over $L+$ $N_{k}^{*}$ periods by taking into account the inventory position $I_{k-1}$, i.e.

$\mathrm{Q}_{k}=\max \left[\sum_{j=1}^{L+N_{k}} F_{k+j-1}+\Phi_{C F U_{L+N_{k}}}^{-1}(C S L)-\right.$
$\left.I_{k-1}, 0\right]$

\section{NUMERICAL COMPARATIVE STUDY}

In this section, we study the relative reduction of the total inventory cost which results from the implementation of the $\left(r_{k}, Q_{k}\right)$ policy compared respectively to the $(1, r, Q)$ policy and to the $\left(r_{k}, Q\right)$ policy for a stationary demand. We assume that the cycle service level is so high that the backlog rate is small. Consequently, the backlog costs can be neglected, and the total inventory cost is composed of the holding cost and the ordering cost.
We assume that the demand and the forecast uncertainty are normally distributed with parameters $\left(m_{D}, \sigma_{D}\right)$ and $\left(0, \sigma_{F U}\right)$. In the $(1, r, Q)$ policy, we use the probability distribution of the demand to calculate the parameters of the policy. To simulate the $\left(r_{k}, Q\right)$ and the $\left(r_{k}, Q_{k}\right)$ policies, the idea is to generate a realization of the demand and a realization of the forecast uncertainty over an horizon composed of $N$ periods. This enables us to calculate the forecasts in each period of the horizon. We consider these forecasts and the probability distribution of the forecast uncertainty to compute the parameters of the $\left(r_{k}, Q\right)$ and $\left(r_{k}, Q_{k}\right)$ policies. The inventory consumption in the system is done by using the real demand.

The relative reduction of the total inventory costs are given by $G_{1}$ and $G_{2}$ as follows :

$$
\begin{aligned}
G_{1} & =\frac{\bar{Z}_{(1, r, Q)}-\bar{Z}_{\left(r_{k}, Q_{k}\right)}}{\bar{Z}_{(1, r, Q)}} \\
G_{2} & =\frac{\bar{Z}_{\left(r_{k}, Q\right)}-\bar{Z}_{\left(r_{k}, Q_{k}\right)}}{\bar{Z}_{\left(r_{k}, Q\right)}}
\end{aligned}
$$

Where $\bar{Z}_{(1, r, Q)}, \bar{Z}_{\left(r_{k}, Q\right)}$ and $\bar{Z}_{\left(r_{k}, Q_{k}\right)}$ are respectively the total inventory costs in the $(1, r, Q)$, the $\left(r_{k}, Q\right)$ and the $\left(r_{k}, Q_{k}\right)$ policies.

We recall that in the $(1, r, Q)$ policy, the system is controlled at the beginning of each period. A fixed quantity $Q$ is ordered whenever the inventory position falls below a static reorder point $r$. A good approximation of the total inventory cost in the $(1, r, Q)$ policy is given by :

$$
\bar{Z}_{(1, r, Q)} \approx h\left[\Phi^{-1}(C S L) \sigma_{D} \sqrt{L+1}+\sqrt{\frac{2 A m_{D}}{h}}\right]
$$

The costs $\bar{Z}_{\left(r_{k}, Q\right)}$ and $\bar{Z}_{\left(r_{k}, Q_{k}\right)}$ are computed numerically.

The numerical values of the parameters used in simulations are as follows :

$N=1000$ periods, $m_{D}=100, L=2$ periods, $C S L=98 \%, A=100$ per order, $h=0.2$ per unit per period.

Results of the simulations are given in this paper for an absolute forecast uncertainty. Results for the case of a relative forecast uncertainty are not presented here.

In the following, we begin by studying the impact of the variability of the forecast uncertainty on $G_{1}$ and $G_{2}$ for a standard deviation of the demand $\sigma_{D}=30$. The curve of $G_{1}$ as a function of $\sigma_{F U}$ is given in Fig. 5. 


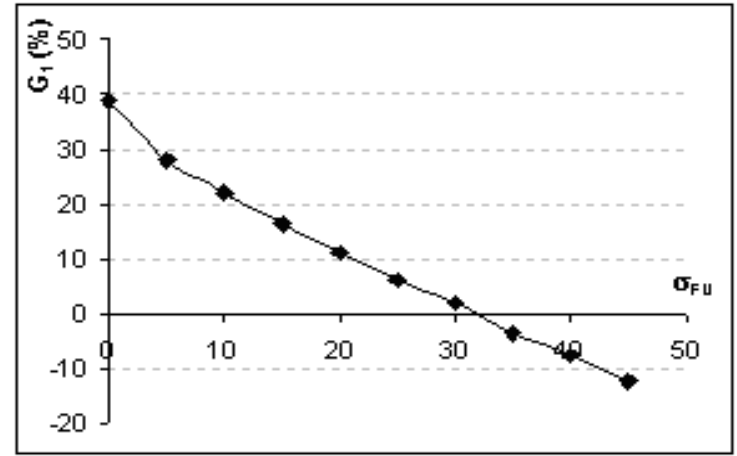

Fig. 5. Impact of the variability of the forecast uncertainty on $G_{1}$

The curve of the relative reduction of the cost shows two parts : (i) a first part where the curve is positive meaning that the average inventory cost in the $(1, r, Q)$ policy is higher than the one in the $\left(r_{k}, Q_{k}\right)$ policy. (ii) a second part where the curve is negative meaning that the average inventory cost in the $(1, r, Q)$ policy is smaller than the one in the $\left(r_{k}, Q_{k}\right)$ policy.

The first part of the curve shows the advantage of using forecasts to control the system, since the relative reduction can go up to $40 \%$ if forecasts are reliable. However, beyond a certain value of the variance of the forecast uncertainty which is close to the variance of the demand, it is more advantageous to use the $(1, r, Q)$ policy and it is not necessary to make forecasts and to control the system with the $\left(r_{k}, Q_{k}\right)$ policy.

We showed in (Babaï and Dallery, 2005) that, when the forecasts are reliable, the implementation of the $\left(r_{k}, Q\right)$ policy implies also considerable benefits compared to the $(1, r, Q)$ policy. Below, we compare the performances of the $\left(r_{k}, Q_{k}\right)$ policy and the $\left(r_{k}, Q\right)$ policy. We study the relative reduction of the cost which results by using the $\left(r_{k}, Q_{k}\right)$ policy compared to the $\left(r_{k}, Q\right)$ policy. The curve of $G_{2}$ as a function of $\sigma_{F U}$ is given in Fig. 6.

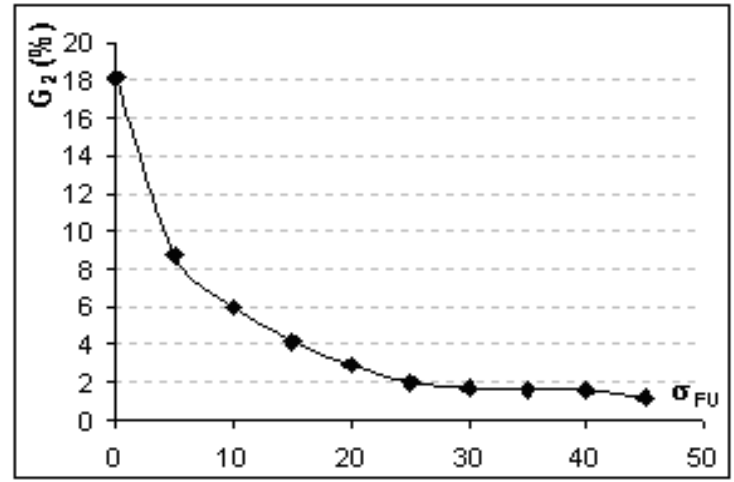

Fig. 6. Impact of the variability of the forecast uncertainty on $G_{2}$
We remark that for a small variability of the forecast uncertainty, the reduction of the cost which results from the use of the $\left(r_{k}, Q_{k}\right)$ policy compared to the $\left(r_{k}, Q\right)$ policy is considerable, since it may reach $18 \%$. This highlights the advantage of using the $\left(r_{k}, Q_{k}\right)$ policy to control the system for reliable forecasts. This reduction of the cost decreases when the variability of the forecast uncertainty increases and falls until $1 \%$. In this part, where the forecasts are not reliable, the $\left(r_{k}, Q_{k}\right)$ policy is not much advantageous compared to the $\left(r_{k}, Q\right)$ policy.

We also study the impact of the demand variability on $G_{1}$ and $G_{2}$ for a fixed forecast uncertainty. We present in Fig. 7 and Fig. 8 the curve of $G_{1}$ and $G_{2}$ as a function of $\sigma_{D}$ for an absolute forecast uncertainty with $\sigma_{F U}=20$.

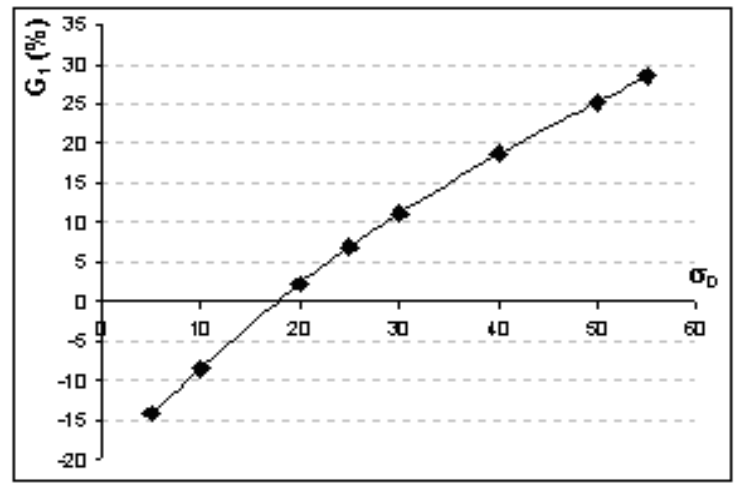

Fig. 7. Impact of the variability of the demand on $G_{1}$

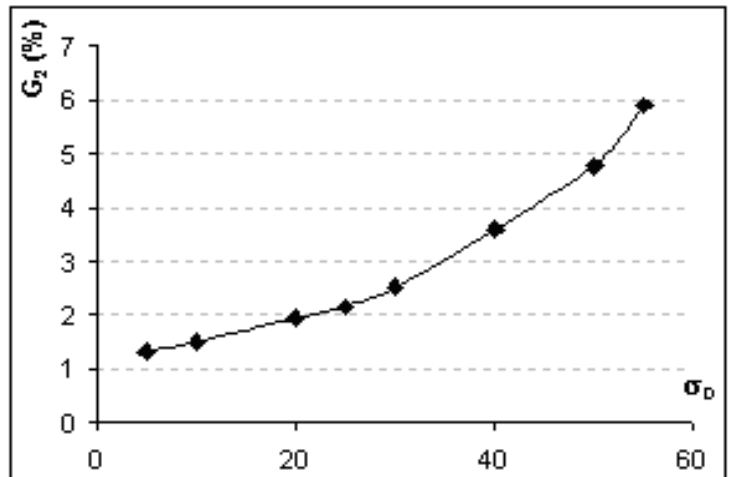

Fig. 8. Impact of the variability of the demand on $G_{2}$

As represented in Fig. 7 and Fig. 8, the higher is the demand variability, the more it will be advantageous to control the system with the $\left(r_{k}, Q\right)$ policy and much more advantageous with the $\left(r_{k}, Q_{k}\right)$ policy. It is obvious that more interesting part of this curve is when the variability of the forecast uncertainty is smaller than the variability of the demand (reliable forecasts).

\section{CONCLUSIONS}

In this paper, we studied two forecast based inventory control policies : the $\left(r_{k}, Q\right)$ policy and 
the $\left(r_{k}, Q_{k}\right)$ policy, and we described the various parameters which characterize them. These parameters are given for two models of the forecast uncertainty, namely : the absolute model and the relative model.

We also provided a numerical comparative study of the $\left(r_{k}, Q_{k}\right)$ policy, the $\left(r_{k}, Q\right)$ policy and the $(1, r, Q)$ policy. We quantified the reduction of the total inventory cost which results from using the $\left(r_{k}, Q_{k}\right)$ policy compared to the $\left(r_{k}, Q\right)$ policy and the $(1, r, Q)$ policy, and we highlight the benefit of using forecasts in the inventory control. This study enabled us to show that if forecast uncertainties are small, i.e. the forecasts are reliable, it is advantageous to use the forecast based inventory control policies. On the other hand, if the forecasts of the demand are not reliable, which corresponds to the case where the forecast uncertainty is high, it is more interesting to use the classical $(1, r, Q)$ policy.

In the future, more work could be done to study the connection between the proposed policies and the MRP policy which is not well highlighted in the literature.

\section{REFERENCES}

Babaï, M. Z. (2005). Politiques de pilotage de flux dans les chaînes logistiques : impact de l'utilisation des prévisions sur la gestion de stocks. Thèse de doctorat, Laboratoire Génie Industriel, Ecole Centrale Paris.

Babaï, M. Z. and Y. Dallery (2005). A study of flow management policies with advance demand information. 7th ISIR Summer School on Supply Chain Inventory Management, Mannheim (Germany).

Chen, F., Z. Drezner, J. K. Ryan and D. SimchiLevi (2000). Quantifying the bullwhip effect in a simple supply chain : The impact of forecasting, lead times, and information. Management Science 46, 436-443.

Graves, S. C. (1999). A single-item inventory model for a nonstationary demand process. Manufacturing Service Operations Management 1, 50-61.

Heath, D. C. and P. L. Jackson (1994). Modeling the evolution of demand forecasts with application to safety-stock analysis in production/distribution systems. IIE Transactions 26, 17-30.

Karlin, S. (1960). Dynamic inventory policy with varying stochastic demands. Management Science 6, 231-258.

Lee, H. L., P. Padmanabhan and S. Whang (1997). Information distortion in a supply chain : The bullwhip effect. Management Science 43, 546-558.
Scarf, H. (1959). The optimality of (s,S) policies in the dynamic inventory problem. Mathematical Methods in the Social Sciences, Stanford University Press, Stanford, California.

Silver, E. A. and H. A. Meal (1973). A heuristic for selecting lot size requirements for the case of a deterministic time-varying demand rate with discrete opportunities for replenishment. Production and Inventory Management Journal 14, 64-74.

Silver, E. A. and R. Peterson (1985). Decision Systems for Inventory Management and Production Planning. John Wiley and Sons, New York.

Zipkin, P. H. (2000). Foundations of Inventory Management. McGraw-Hill, USA. 